\title{
Assessment of Stevia rebaudiana Bertoni Genotypes via Morpho-Agronomic Traits under Two Light Conditions
}

\author{
Dhulfiqar Aamer Abdulameer1, Mohamad Bin Osman1, Zulkefly Sulaiman1,2, Mohd Rafi Yusop",3, \\ Shamsiah Abdullah4, Parisa Azizi' ${ }^{1}$, Qusay Abdulhamza Muttaleb ${ }^{1,5}$
}

\author{
${ }^{1}$ Department of Crop Science, Faculty of Agriculture, Universiti Putra Malaysia, Serdang, Malaysia \\ ${ }^{2}$ Institute of Plantation Studies, Universiti Putra Malaysia, Serdang, Malaysia \\ ${ }^{3}$ Laboratory of Food Crops, Institute of Tropical Agriculture, Universiti Putra Malaysia, Serdang, Malaysia \\ ${ }^{4}$ Faculty of Plantation and Agrotechnology, Universiti Teknologi MARA, Shah Alam, Malaysia \\ ${ }^{5}$ Technical Institute of Babel, Al-Furat Al-Awsat Technical University, Al Hillah, Iraq \\ Email: dhualfiqara@yahoo.com
}

How to cite this paper: Abdulameer, D.A., Osman, M.B., Sulaiman, Z., Yusop, M.R., Abdullah, S., Azizi, P. and Muttaleb, Q.A. (2018) Assessment of Stevia rebaudiana Bertoni Genotypes via Morpho-Agronomic Traits under Two Light Conditions. American Journal of Plant Sciences, 9, 1403-1413. https://doi.org/10.4236/ajps.2018.97102

Received: January 27, 2018

Accepted: June 12, 2018

Published: June 15, 2018

Copyright ( 92018 by authors and Scientific Research Publishing Inc. This work is licensed under the Creative Commons Attribution International License (CC BY 4.0).

http://creativecommons.org/licenses/by/4.0/

\section{cc) (7) Open Access}

\begin{abstract}
Stevia rebaudiana Bertoni, a non caloric natural sweetner is currently the available substitute to sugar. It is a genus of about 150 species of herbs and shrubs, a compositae and native to Paraguay. However, stevia is a short day plant with almost a constant day length $<12$ hours in Malaysia stevia generated to flower early. Therefore, the aim of the study was to investigate the effect of different day length on Stevia rebaudiana genotypes in Malaysia. The experiment was undertaken during December 2016 to April 2017 in the Faculty of Design and Architecture, Universiti Putra Malaysia, Serdang, Selangor, Malaysia. Eight stevia genotypes namely (CHV1, Morita2, MS012, MS012 (4x), SA18, TPU, and hybrids IIUM-F1 and UiTM-H2) were evaluated for the agronomic traits under two conditions: sun light $(<12$ hours $)$ and simulated light (>14 hours) using a factorial experiment. The agronomic performance of Stevia rebaudiana was significantly in long day length ( $>14$ hours) environment comparing with short day length ( $<12$ hours) environment. Stevia plants under sun light start to flower after seven weeks, from the other hand stevia plants under simulated light did not flower. All stevia genotypes showed a high performance under long day length ( $>14$ hours) environments.
\end{abstract}

\section{Keywords}

Stevia rebaudiana, Propagation, Sun Light, Simulated Light

\section{Introduction}

Stevia rebaudiana Bertoni is a perennial herb containing natural sweetening 
compounds which are 230 times sweeter than sucrose with no calorific value. It was first discovered by a Swiss botanist, Moises Santiago Bertoni and this plant has been exploited ever since. Stevia belongs to Asteraceae family. According to Soejarto, et al. [1] Stevia rebaudiana Bertoni was confirmed to give the sweetest essence than 240 stevia species. It is a good supply of carbohydrate, protein, crude fiber and minerals [2]. The sweetness of stevia comes from compounds known as diterpene glycosides. Among 10 sweet glycosides in stevia, but barely two are important, namely stevioside and rebaudioside A [3]. However, stumpy and rough seed germination (due to its small seed size) and slow establishment of seedlings deserve its propagation during vegetative means [4]. Micro-cutting is able to promote rooting development for stevia cutting with the presence of mist-chamber propagation box [5]. Stevia substance is maximum immediately before flowering. Flowering is generated by short day length. With almost a constant day length of $<12$ hours widespread throughout the year in Malaysia, stevia plants are triggered to flower early, roughly 6 weeks following planting from stem cuttings, usually before being able to gather maximum biomass [6]. Therefore, stevia plants show of very short vegetative period, resulting in low leaf yield and as a result low content of sweetening compounds. For producing or selecting stevia varieties which may be appropriate under tropical situation, the first step is to study the agronomic performance among the available genotypes under two conditions sun light (normal condition) with day length of $<12$ hours and extended light (stimulated condition) with day length $>14$ hours. Stevia has the potential to become a wide-ranging alternate for sugar for the Malaysian population, its products for certain local market specially for medical value are even more promising because there are lots of diabetic patients in the country so its benefit for them. However, Malaysia still lacks of suitable varieties and production technologies, while some suitable stevia varieties have been successfully developed in few countries like Japan and India. Therefore there is need to carry out appropriate research and development program in order to develop suitable local varieties. The aim of the research therefore to evaluate the agronomic traits among available Stevia rebaudiana genotypes in Malaysia under two conditions sun light and simulated light (Figure 1 and Figure 2).

\section{Materials and Methods}

\subsection{Experimental Site}

The study was conducted from December 2016 to April 2017, at Faculty of Design and Architecture, Universiti Putra Malaysia, Serdang, Selangor, Malaysia. The experiments were carried out in two different places, in open sunlight and in extended light $>14$ hours.

\subsection{Experimental Design}

The study was accomplished in Randomized Complete Block Design (RCBD) 


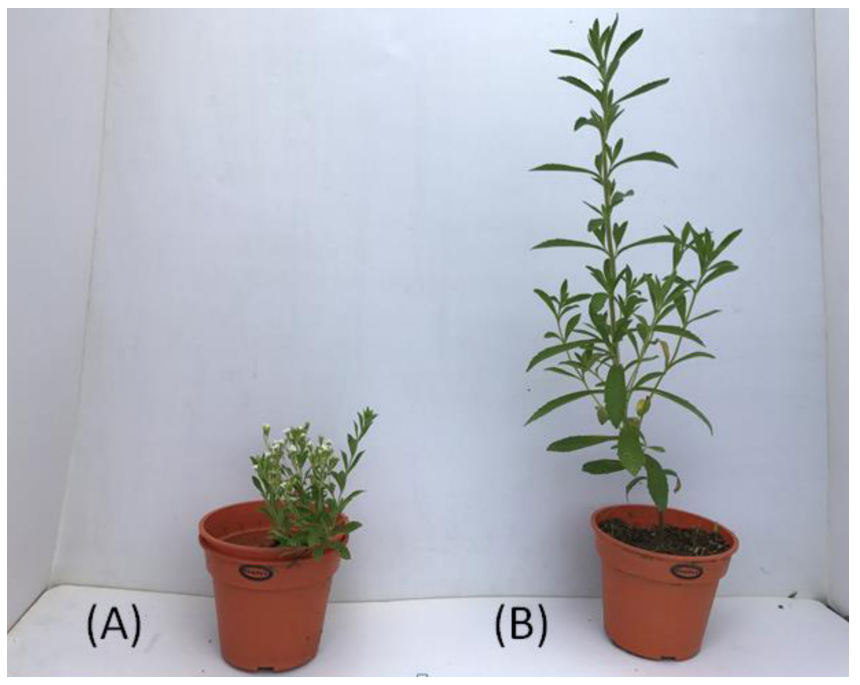

Figure 1. Accession CHV1 under two conditions. (A) Sun light: flowered after 49 days; (B) Extended light: no flowering after 134 days.

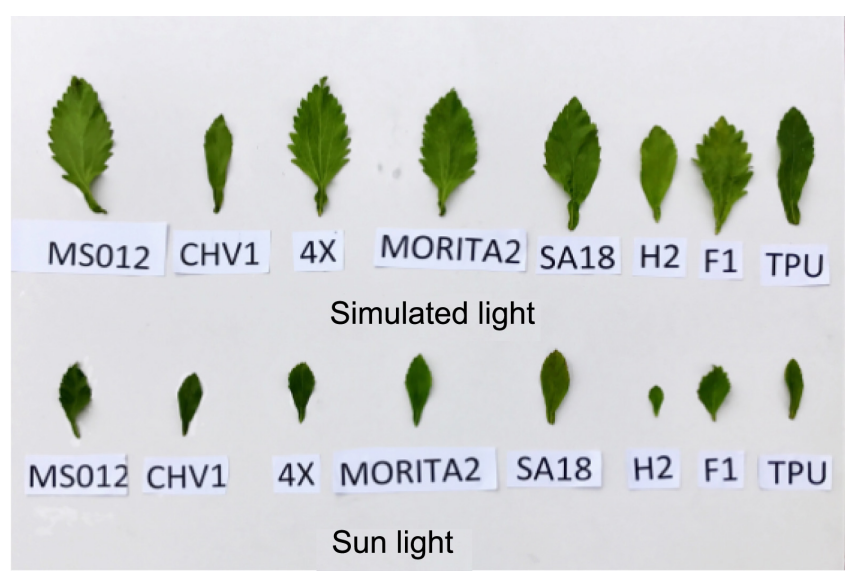

Figure 2. Stevia rebaudiana Bertoni leaves under two conditions.

with three replications. Each block consisted of 48 plots, where each 6 plots represented by one accession.

\subsection{Soil Mixture}

The experimental soil was mixed with loam, sand and coco husk. The proportion of the mixture was done at the ratio of 1:3:3 which represent a portion of soil, three portions of sand and three portions of coco husk. All portions were mixed by using soil mixer. The soil mixture was filled to the brim into " $8 \times 8$ " size polybags.

\subsection{Collection of Stevia Accessions}

Stevia accessions were collected from three resources namely Universiti teknologi Mara (UiTM), International Islamic Universiti Malaysia (IIUM), and Universiti Putra Malaysia (UPM). 
Six stevia accessions and two hybrids were collected (Figure 3). The stevia accessions were placed under rain shelter located at Field 2, Universiti Putra Malaysia, Serdang, Selangor. Each accession exhibited diverse ranges of morphological characteristics.

\subsection{Propagation of Stevia Collection}

\subsubsection{Micro-Cutting}

All stevia accessions were propagated through stem micro-cutting. Stem cutting propagation allow multiplication of stevia accessions and maintaining the genetic duplication of each accession. The stem was cut and collected from the terminal part of the shoot. The stem was cut at about $4 \mathrm{~cm}$ or two nodes apart. In order to induce root formation, rooting powder containing indole-3-butyric acid (IBA) was used at approximately $1.5 \mathrm{~cm}$ deep and stem was dipped into it. Application of IBA was reported to be efficient in improving and stimulating adventitious roots formation [7].

\subsubsection{Propagation Box}

The stems were placed in the propagation box or mist-chamber box. The propagation box consisted of two layers of media which were perlite on the top and clay ball at the bottom as invented by Yahya, A., Nor'ain, A. R. and Ab Kahar, S. [8]. The mist provide appropriate environment for cutting to develop and promote root formation. Water was poured into media until the perlite was totally soaked. The stem cutting was placed into the media and left until it started to produce roots in two weeks. When the rooting was complete then the plants were transferred into the polybags (Figure 4). For this study, 40 plants were propagated for each stevia accession.

\subsubsection{Acclimatization of Stevia Cutting}

In providing an appropriate condition for adaptation or hardening of the young

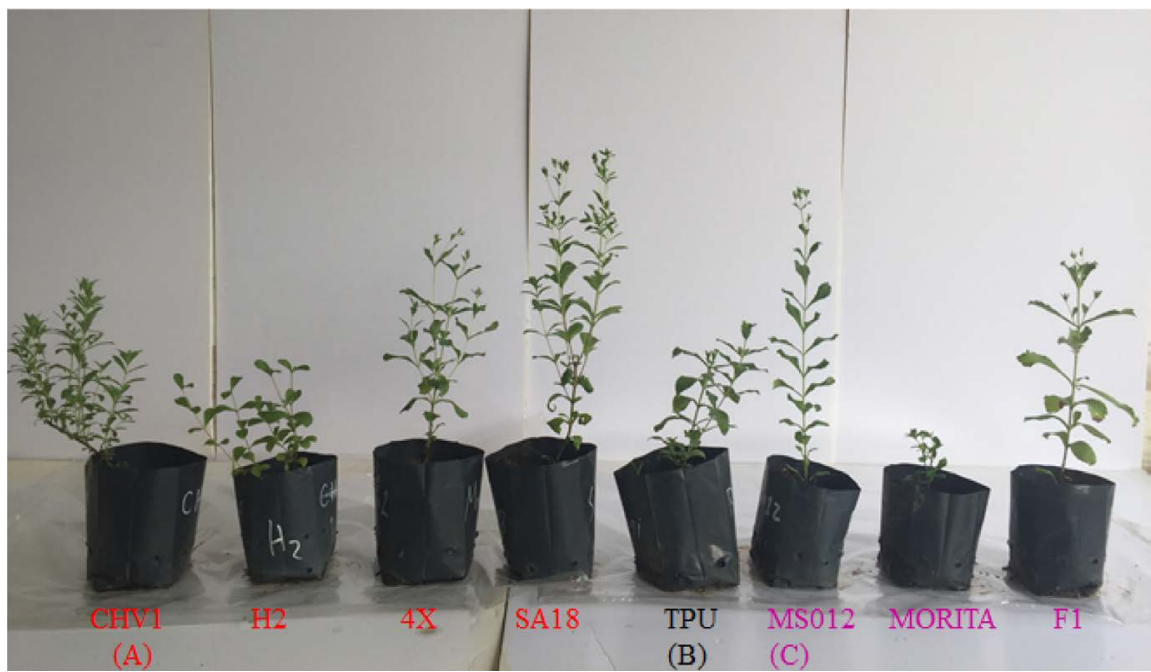

Figure 3. Eight stevia genotypes collected from three resources (A) UiTM, (B) UPM and (C) IIUM. 

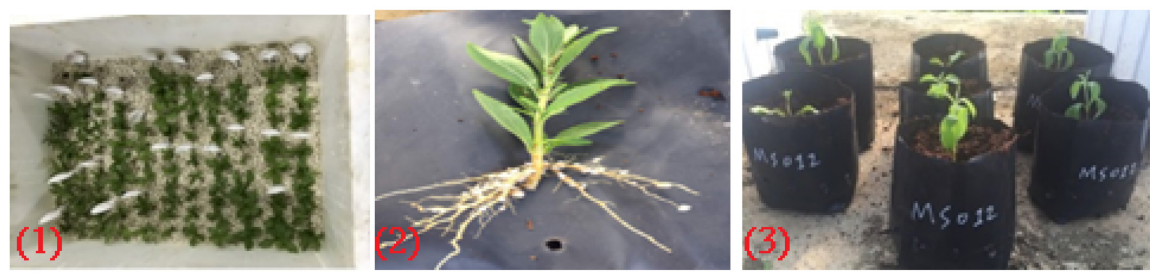

Figure 4. Steps for propagation of Stevia rebaudiana genotypes.

plants, shade was installed. Fifty percent of shade was placed as a cover on the top of propagation site. The shade was fixed to the young plants to avoid direct sunlight and avoiding desiccation.

\subsection{Evaluation Agronomic Performance of Selected Stevia Accessions}

In this study, the eight accessions were placed in the field to observe and evaluate the performance of each accession. For this assessment study, simulated light was set up to evaluate the growth performance of collected stevia accessions. For simulated light, standard white light was used in this experiment. The bolds were hung onto of the plants and each accession was placed under them. The light was deal with an automatic timer to extend the light for an hour before 7 am and for an hour after $7 \mathrm{pm}$. This was provided $>14$ hours of required day light to the stevia accessions. In the case of normal sunlight, the stevia accessions were placed under normal condition without any light exposure.

\subsection{Agronomical Traits}

\subsubsection{Plant Height (cm)}

Plant height was measured in each treatment from the medium level (base of the plant) until the tip of the plant using a steel meter ruler.

\subsubsection{Stem Diameter ( $\mathrm{mm}$ )}

Plant stem diameter was measured using digital vernier caliper at $1 \mathrm{~cm}$ above the base of the plant.

\subsubsection{Number of Leaves (per Plant)}

The number of leaves was determined by counting all leaves in plant including small leaves.

\subsubsection{Leaf Ratio}

The length and breadth of leaf were measured using a steel meter ruler and ratio was calculated by length/breadth.

\subsubsection{Number of Branches (per Plant)}

The number of branches was determined by counting all the branches per plant.

\subsubsection{Days to Flowering}

It was measured by counting the days from the day first until the plant began to flowering. 


\subsubsection{Fresh and Dry Weight (g)}

The fresh weight of the plant was determined by using sensitive weighing balance (model A\&D Co. Ltd. model FX-1200i Japan). After taking the fresh weight, each plant was placed in envelope and dried in the oven at $50^{\circ} \mathrm{C}$ for 48 hours until a constant weight was gained for the dry weight determination.

\section{Statistical Analysis}

Statistical analyses were conducted based on the eight parameters using SAS version 9.4, through analysis of Variance (two-way ANOVA) factorial experiment separately for all agronomic characteristics. Prior to data analysis, all variables were subjected to normality test. Mean comparison was done using Duncan test for each agronomic characteristics separately at 0.05 level. Furthermore, multiple regression analyses were conducted to test the effects on agronomical characteristics. As, regression analysis is one of the most commonly used methods in exploring predictor variables, thus all variables were predicted through using multiple regression model which consisted of five predicting variables such as height $\left(\chi_{1}\right)$, number of branches $\left(\chi_{2}\right)$, stem girth $\left(\chi_{3}\right)$, number of leaves $\left(\chi_{4}\right)$ and leaf ratio $\left(\chi_{5}\right)$. Based on these factors the prediction equation was given as:

$$
\hat{Y}=\beta_{0}+\beta_{1} \chi_{1}+\beta_{2} \chi_{2}+\beta_{3} \chi_{3}+\beta_{4} \chi_{4}+\beta_{5} \chi_{5}
$$

where;

$$
\begin{aligned}
& \hat{Y}=\text { Fresh weight. } \\
& \chi_{1}=\text { height. } \\
& \chi_{2}=\text { number of branches. } \\
& \chi_{3}=\text { stem girth. } \\
& \chi_{4}=\text { number of leaves. } \\
& \chi_{5}=\text { leaf ratio. } \\
& \mathcal{E}=\text { random error. }
\end{aligned}
$$

\section{Result and Discussion}

\section{Evaluation of the Agronomic Performance}

The results of agronomic performance under two conditions (i.e. sun light and extended light) for all accessions showed that the all agronomic characteristics were increased under extended light. These results showed that all accessions went to flowering stage almost after seven weeks under sun light meanwhile only three accessions such as $\mathrm{H} 2$, MS012 and SA18 entered to flowering stage under extended light, whereas the time to flowering for these accessions were almost 20 weeks. Comparing the plant height under these two conditions indicated that all over ally accessions under extended light had more vegetative growth and therefore the plant height was almost three times higher more than plants kept under sun light. The number of leaves among plants under extended light also increased (86\%) as compared to plants kept under sunlight. The stem girth and number of branches were increased with $179 \%$ and $9 \%$ respectively. However, the fresh weight increased with $728 \%$. The highest difference of $918 \%$ was ob- 
served in dry weight for plants which were kept under extended light as compared to accessions kept under sun light. It could be increased due to long period of vegetative growth (Table 1).

To evaluate the effect of accession and light condition on agronomic characteristics, data were analyzed based on two-way ANOVA (factorial experiment) for all agronomic characteristics. All the agronomic characteristics were normally distributed and the results showed the both factors accession and light condition and their interaction between these factors was highly significant $(p<0.05)$ on plant height. For the number of branches the results showed that there was higher significant for the accession and the interaction between accessions and light. Meanwhile, for the stem girth it was higher significant for the two factors accessions and light and it showed significant with the interaction between light and accession. On the other hand replications, accession, light and interaction between light and accessions for the number of leaves were higher significant. The results for the leaf ratio showed that there were higher significant deferens between the accessions and it was significant different for the interaction between accession and light. However, the results of fresh and dry weight showed higher significance for accession, light and the interaction between light and accession.

However, the days to flowering was analyzed only for the sun light due to the constant value under extended light. The results in regard to number of days to flower between accessions were found with non-significant $(p>0.05)$ difference. Meanwhile, the coefficient of variance for all agronomic characteristics ranged between 3.14 to 30.6 which was in acceptable range (Table 2).

All the parameters were correlated to know the relationship between all selected parameters and stevia accessions. The Pearson correlation coefficient between plant height and stem girth was strongly positive and showed significant relationship $(\mathrm{r}=0.891, p<0.01)$ as given in (Table 3$)$. The relationship between plant height and number of leaves was positively moderate and significant $(\mathrm{r}=$ $0.570, p<0.01$ ). The relation between the plant height with fresh weight, dry weight and days to flowering showed strongly positive correlated $(r=0.928$,

Table 1. Percent increase of agronomic performance of stevia accessions under $>14$ hours of day length.

\begin{tabular}{cccc}
\hline Parameters & Sun light & Extended light & $\%$ \\
\hline Days to flowering & 7 weeks & $\begin{array}{c}\text { No flowering } \\
\text { (except in H2, MS012 and SA18) }\end{array}$ & - \\
Height & 19.05 & 69.96 & $267 \%$ \\
No. of leaves & 93.44 & 174.25 & $86 \%$ \\
Stem girth & 2.49 & 6.95 & $179 \%$ \\
No. of branches & 4 & 4.38 & $9 \%$ \\
Fresh weight & 2.74 & 22.67 & $728 \%$ \\
Dry weight & 0.88 & 8.96 & $918 \%$ \\
\hline
\end{tabular}


Table 2. Analysis of variance for the effect of day length on agronomic performance in Stevia rebaudiana Bertoni.

\begin{tabular}{|c|c|c|c|c|c|c|c|c|c|}
\hline Source & d.f & Height $(\mathrm{cm})$ & No. branches & $\begin{array}{l}\text { Stem girth } \\
(\mathrm{mm})\end{array}$ & No. leaves & Leaf ratio & $\begin{array}{c}\text { Fresh } \\
\text { weight }(\mathrm{g})\end{array}$ & $\begin{array}{c}\text { Dry } \\
\text { weight }(\mathrm{g})\end{array}$ & $\begin{array}{l}\text { Days to } \\
\text { flowering }\end{array}$ \\
\hline Rep & 2 & 5.35 & 0.51 & 0.41 & $331.49^{* *}$ & 0.24 & 14.16 & 5.38 & 6.75 \\
\hline Accession & 7 & $526.47^{* *}$ & $170.08^{\star *}$ & $4.73^{* *}$ & $25,093.84^{* *}$ & $2.06^{* *}$ & $168.38^{* *}$ & $27.09^{\star *}$ & 47.81 \\
\hline Light & 1 & $61,184.76^{\star *}$ & 2.85 & $474.20^{\star *}$ & $153,899.20^{* *}$ & 0.56 & $9432.38^{\star \star}$ & $1554.04^{\star *}$ & -- \\
\hline Accession ${ }^{\star}$ light & 7 & $229.06^{\star *}$ & $5.10^{* *}$ & $1.84^{*}$ & $14,720.51^{* *}$ & $0.70^{*}$ & $140.91^{\star *}$ & $23.76^{\star *}$ & -- \\
\hline $\begin{array}{l}\text { Coefficient of } \\
\text { Variation }\end{array}$ & & 9.09 & 21 & 15.52 & 3.14 & 17.6 & 23.39 & 30.64 & 25.36 \\
\hline
\end{tabular}

${ }^{*}$ Significance at $p<0.05,{ }^{* *}$ Significance at $p<0.01$.

Table 3. Correlation matrix between agronomic characteristics of stevia accessions.

\begin{tabular}{|c|c|c|c|c|c|c|c|c|}
\hline & HEIGHT & NO. BRANCHES & $\begin{array}{l}\text { STEM } \\
\text { GIRTH }\end{array}$ & NO. LEAVES & $\begin{array}{c}\text { FRESH } \\
\text { WEIGHT }\end{array}$ & DRY WEIGHT & $\begin{array}{c}\text { DAYS TO } \\
\text { FLOWERING }\end{array}$ & $\begin{array}{l}\text { LEAF } \\
\text { RATIO }\end{array}$ \\
\hline HEIGHT & 1 & & & & & & & \\
\hline NO. BRANCHES & 0.049 & 1 & & & & & & \\
\hline STEM GIRTH & $0.891^{* *}$ & -0.045 & 1 & & & & & \\
\hline NO. LEAVES & $0.570^{* *}$ & $0.540^{\star *}$ & $0.509^{* *}$ & 1 & & & & \\
\hline FRESH WEIGHT & $0.928^{\star *}$ & 0.023 & $0.892^{\star *}$ & $0.585^{\star *}$ & 1 & & & \\
\hline DRY WEIGHT & $0.913^{* *}$ & 0.037 & $0.885^{\star *}$ & $0.610^{* *}$ & $0.989^{* *}$ & 1 & & \\
\hline $\begin{array}{c}\text { DATE TO } \\
\text { FLOWERING }\end{array}$ & $0.937^{* *}$ & 0.066 & $0.913^{* *}$ & $0.595^{* *}$ & $0.864^{\star *}$ & $0.847^{* *}$ & 1 & \\
\hline LEAF RATIO & 0.153 & $0.545^{\star *}$ & 0.046 & $0.476^{\star *}$ & 0.129 & 0.125 & 0.163 & 1 \\
\hline
\end{tabular}

${ }^{* *}$ Correlation is significant at the $p<0.01$ level.

0.913 and 0.937 at $p<0.01)$.

The relationship for the number of branches was positive moderate and significant $(p<0.05)$ with number of leaves $(\mathrm{r}=0.540)$ and leaf ratio $(\mathrm{r}=0.545)$. The correlation coefficient for the stem girth showed a positive moderate and significant $(p<0.05)$ with the number of leaves $(\mathrm{r}=0.509)$, strongly significant with the fresh weight $(r=0.829)$ and dry weight $(r=0.885)$ at $p<0.01$. The relationship between stem girth and days to flowering was strongly correlated with significant difference $(r=0.913, p<0.01)$. Besides, the relationship for the number of leaves was moderate significant difference $(p<0.01)$ with the fresh weight, days to flowering and leaf ratio $(r=0.585, r=0.595, r=0.476)$. The relationship between number of leaves and dry weight was strongly correlated ( $\mathrm{r}=$ $0.610)$ and showed a significant impact $(p<0.01)$. Meanwhile, for the fresh weight it showed a strong significant relationship with the days to flowering $(r=$ $0.864, p<0.01)$ and it showed a very strong significant relationship with the dry weight too $(r=0.989, p<0.01)$. In last, the strong significant correlation coefficient was between the dry weight and the days to flowering $(\mathrm{r}=0.847)$ at $p<$ 0.01 . 
Moreover, the results regarding multiple regression analyses were displayed a significant values for predictors of fresh weight as dependent variables under sun light and extended light conditions. The standardized regression coefficient (Beta) was used to assess the effect of each agronomical characteristic (number of leaves, height, stem girth, number of branches and leaf ratio) to the prediction of fresh weight. Standardized beta coefficient $(\beta)$ means that the values for each of the independent variables have been converted to the same scale so that comparisons can be made between them. Because of the common unit of the measurement, it could be possible to define which predictor was most influential. Each standardized beta coefficient $(\beta)$ value could differ from -1.00 to +1.00 and it was calculated for each predictor variable.

The results in (Table 4) revealed the regression analyses of fresh weight under sun light and extended light. According to the regression model, the relationship between predictor and dependent variable under sun light was not significant ( $p>0.137)$ and the regression value was $\mathrm{R}^{2}=0.163$ that meant that all independent variables explained $16.3 \%$ of variance in fresh weigh meanwhile the regression model under extended light was significant $(p<0.001)$ and the $\mathrm{R}^{2}=0.845$ revealed that all independent variables explained $84.5 \%$ of variance in fresh weigh. However, the results under extended light indicated that all independent variables except number of branches and leaf ratio are statistically significant different $(p<0.01)$ and the highest effect was observed in height $(\beta=0.62)$ followed by number of leaves $(\beta=0.54)$ and the lowest effect was observed in stem girth $(\beta=0.51)$. All these three variables positively affected on fresh weight whereas under sunlight condition none of these five factors showed a significant effect on fresh weight of stevia.

\section{Discussion}

Micro-cutting methods showed significant result in stevia propagation with the application of rooting hormone and the propagation box invented by Yahya, A., Nor'ain, A. R. and Ab Kahar, S. [8]. An increase in rooting and lowering the decrease in-rooting duration for the cutting were observed with the application of micro-cutting. Previously, Osman, M., et al. [5] was concluded that micro-cutting

Table 4. Results of hierarchical regression analysis for stevia accessions.

\begin{tabular}{cccccccccccc}
\hline Variables & Extended light & \multicolumn{1}{c}{ Sunlight } \\
\hline & $\mathrm{B}^{+}$ & SE. $\mathrm{B}^{++}$ & Beta & t value & p value & $\mathrm{B}^{+}$ & SE. $\mathrm{B}^{+}$ & Beta & t value & $p$ value \\
\hline (Constant) & -18.17 & 3.43 & - & $-5.29^{* *}$ & $<0.001$ & 0.33 & 0.96 & - & 0.34 & 0.74 \\
Height $\left(\mathrm{X}_{1}\right)$ & 0.17 & 0.03 & 0.62 & $5.89^{* *}$ & $<0.001$ & -0.01 & 0.03 & -0.05 & -0.14 & 0.892 \\
No. of branches $\left(\mathrm{X}_{2}\right)$ & -0.29 & 0.15 & -0.38 & -1.99 & 0.075 & -0.03 & 0.04 & -0.42 & -0.81 & 0.435 \\
Stem girth $\left(\mathrm{X}_{3}\right)$ & 1.52 & 0.35 & 0.51 & $4.39^{* *}$ & 0.001 & -0.06 & 0.29 & -0.07 & -0.19 & 0.85 \\
No of .leaves $\left(\mathrm{X}_{4}\right)$ & 0.02 & 0.01 & 0.54 & $3.71^{* *}$ & 0.004 & 0.01 & 0.01 & 1.02 & 1.81 & 0.101 \\
Leaf ratio $\left(\mathrm{X}_{5}\right)$ & 0.74 & 0.83 & 0.16 & 0.89 & 0.397 & -0.06 & 0.36 & -0.05 & -0.15 & 0.881 \\
\hline
\end{tabular}

${ }^{+}$Unstandardized regression coefficient. ${ }^{++}$Standard error of regression coefficient. 
is able to promote rooting development for stevia cutting with the presence of mist-chamber propagation box.

Through the trial conducted, under $>14$ hours extended day length showed significant difference in term of stevia growth due to the long vegetative period [6] and [9] Yadav, A.K., et al. stated that stevia growth is affected when stevia started to produce flowers in which disrupted the growth, leaves production and level of sweetness. Based on the result collected, under $>14$ hours extended day length able to increase the number of day to flower in which help in term of stevia development compared to normal day length. Malaysian day length about 12 hours as reported by Kafle, G. G. [10] where exposure to more than 14 hours of day length increased the chance of stevia flowering up to 80 percent as early as after sixty day of exposure. This indicated that in order to avoid pre-mature flowering and increased stevia growth, extended $>14$ hours day length is needed to be introduced.

Based on the correlations results in Table 3, days to flower affect the growth parameters of stevia accessions especially on plant height, fresh weight and dry weight. According to previous study by Abdullateef, R. A. and Osman, M. B. [11], stevia is a short day plant of approximately day length of 13 hours. The statement supported Tan, S., et al. [6] which stated that stevia in Malaysia developed pre-mature flower due to short of day length in Malaysia which hinder the growth of stevia and limit the yields which also in agreement with finding by Armizatul, S., et al. [12]. These indicate that the growth of stevia in Malaysia is limited by the short day length which triggers early flowering.

\section{Conclusions}

Micro-cutting demonstrated effective method in propagating stevia accession through cutting. By providing more conducive environment and application of rooting hormone, number of cuttings for propagated stevia accessions can be increased with higher survival rate.

The collected stevia accessions showed medium performance due to the short-day length in Malaysia which is up to 12 and a half hours. Short day length induced the formation of pre-mature or early flowering which inhibited stevia growth and lowered the sweetness level in stevia. In this study, an exposure to $>14$ hours of day length through simulated day length showed improved performance where the application of $>14$ hours day length increased the growth and inhibited early flowering of the experimental accessions. This indicates that with the application of $>14$ hours of day length, it is able to induce the mass production and delay flowering of stevia accessions. This helps in overcoming the pre-mature or early flowering problem of stevia accessions propagated under Malaysian climate.

\section{References}

[1] Soejarto, D., et al. (1983) Potential Sweetening Agents of Plant Origin. II. Field Search for Sweet-Tasting Stevia Species. Economic Botany, 37, 71-79. 
https://doi.org/10.1007/BF02859308

[2] Abou-Arab, A.E., Abou-Arab, A.A. and Abu-Salem, M.F. (2010) Physico-Chemical Assessment of Natural Sweeteners Steviosides Produced from Stevia rebaudiana Bertoni Plant. African Journal of Food Science, 4, 269-281.

[3] Singh, S.D. and Rao, G.P. (2005) Stevia: The Herbal Sugar of 21st Century. Sugar Tech, 7, 17-24. https://doi.org/10.1007/BF02942413

[4] Smitha, G. and Umesha, K. (2012) Vegetative Propagation of Stevia [Stevia rebaudiana (Bertoni) Hemsl.] through Stem Cuttings. Journal of Tropical Agriculture, 50, 72-75.

[5] Osman, M., et al. (2013) Factors Affecting Microcuttings of Stevia Using a Mist-Chamber Propagation Box. The Scientific World Journal, 2013, Article ID: 940201. https://doi.org/10.1155/2013/940201

[6] Tan, S., et al. (2008) Preliminary Evaluation and Selection of Stevia under Malaysian Conditions. Journal of Tropical Agriculture and Food Science, 36, 171-177.

[7] Ludwig-Müller, J., Vertocnik, A. and Town, C.D. (2005) Analysis of Indole-3-Butyric Acid-Induced Adventitious Root Formation on Arabidopsis Stem Segments. Journal of Experimental Botany, 56, 2095-2105. https://doi.org/10.1093/jxb/eri208

[8] Yahya, A., Nor'ain, A.R. and Ab Kahar, S. (2009) Adventitious Rooting in Microcuttings of Selected Indigenous Landscape Trees of Malaysia. International Journal of Agriculture and Biology, 11, 419-424.

[9] Yadav, A.K., et al. (2011) A Review on the Improvement of Stevia [Stevia rebaudiana (Bertoni) ]. Canadian Journal of Plant Science, 91, 1-27. https://doi.org/10.4141/cjps10086

[10] Kafle, G.G. (2011) Some Studies on the Physiology of Stevia rebaundiana (Bertoni). Faculty of Sciences, Engineering and Health, CQ University, Norman Gardens.

[11] Abdullateef, R.A. and Osman, M.B. (2011) Effects of Visible Light Wavelengths on Seed Germinability in Stevia rebaudiana Bertoni. International Journal of Biology, 3,83 .

[12] Armizatul, S., et al. (2010) Effects of Night Break on Stevia rebaudiana. The Role of Plant Physiology in Climate Change Adaptation in Climate Change Adaptation and Mitigation and Mitigation Conference, 14.

https://scholar.google.com/scholar?hl=en\&as_sdt=0\%2C5\&q=Armizatul\%2C+S.\%2 C+et+al.+\%282010\%29+Effects+of+Night+Break+on+Stevia+rebaudiana.+The+Ro le+of+Plant+Physiology+in+Climate+Change+Adaptation+in+Climate+Change+A daptation+and+Mitigation+and+Mitigation.\&btnG= 